\title{
Blogs and e-Portfolios: can they support reflection, evidencing and dialogue in teacher training?
}

\section{Simon Cotterill}

Newcastle University, UK

Karen Lowing

Newcastle University, UK

\section{Karl Cain}

Newcastle University, UK

\section{Rachel Lofthouse}

Newcastle University, UK

\section{Cheryl Mackay}

Newcastle University, UK

\section{Joanne McShane}

Newcastle University, UK

\section{David Stancliffe}

Newcastle University, UK

\section{David Wright}

Newcastle University, UK

\section{Abstract}

A blog with explicit support for structured skills/competencies and community publishing was integrated within an e-Portfolio and evaluated with three successive cohorts of PGCE secondary students at Newcastle University in order to support reflections on practice, weekly lesson evaluations, and to evidence Teaching Quality Standards (TQS).

The technologies were initially piloted with a single subject (English with Drama) in 2007/8, with roll out to all thirteen PGCE programmes in 2008/9 (156 students and seven tutors). Focus groups and questionnaires were used to investigate students' perceptions of using 
the blog to support both reflection and evidencing, to identify factors relating to engagement, and to explore informal use of external social networking with course-mates. Tutors' views were also captured.

Students accessed the portfolio an average of sixty three times each (the range being from 4 to 254 ) and uploaded a total of 1,785 files over a ten month period in $2008 / 9$. Students made an average of 27 blog entries each (36\% published to a community). Analysis of questionnaire data (37\% response rate) indicated that students liked the approach of linking one item of evidence to multiple TQS and feeling 'in touch' whilst on placement. Students (89\%) used external social networking sites (47\% of students used them for course-related purposes). The main barrier to engagement with the e-Portfolio was the perceived lack of time on a busy course.

This study informs debate on the level of structure required in e-Portfolios/blogs for vocational subjects and factors relating to engagement and concurrent use of formal/institutional and informal social networking sites.

Key words: e-Portfolios; blogs; reflection.

\section{Introduction}

In common with many other professional disciplines, teaching has seen increasing demands for reflective practitioners with the skills and attitudes necessary for continuing professional development (Hatton and Smith, 1995). In addition, skills in evidencing achievement and ongoing development within professional frameworks are important for initial qualification, early professional development, annual performance reviews, and ongoing career progression. As such, electronic portfolios (e-Portfolios), which can be used to facilitate both reflection and evidencing, have applicability to teaching. In addition, the technologies also bring new means of supporting dialogue between students and tutors, and also between peers. This may help meet the changing needs and expectations of new generations of learners who have grown up with social networking and other Web 2.0 technologies. There is a need for research into the dynamics and implications of these new technologies. This ranges from basic questions around the levels of engagement with 
these technologies to more complex issues, such as potential changes in reflective learning when writing (and reading) in a shared blogging 'space', rather than in a private diary. This action research study provides evaluation of an e-Portfolio and blog within Initial Teacher Training (ITT). Many of the findings have broader applicability in other contexts where there are common challenges, such as those related to engagement and tensions between reflection and assessment.

\section{Context}

This study of e-Portfolio and blogging was conducted at Newcastle University on Postgraduate Certificate in Education (PGCE) programmes for secondary education. There are thirteen programmes in seven discipline areas (English with Drama, Geography, History, Mathematics, Modern Languages, Religious Education, and Sciences). The programmes are of ten month duration and lead to Qualified Teacher Status (QTS) as defined by the Training and Development Agency for Schools (TDA) (TDA, 2007).

\section{E-Portfolio and blog}

This study used the ePET portfolio which was developed at Newcastle University over the course of a number of collaborative projects (Cotterill et al., 2005; Cotterill et al., 2006). A new blog was developed for this e-Portfolio in 2007 as part of the JISC funded 'EPICS-2' regional project. The blog can be personalised and learners have the option of making each entry private, public or shared with defined communities. A key feature of the blog was its design to include explicit support for structured learning outcomes/skill sets (Cotterill et al., 2007; Cotterill et al., 2008). The learner has the option to link each blog entry with one or more skills, these blog entries are then automatically cross-referenced in the evidence area of the portfolio which is structured around the skill set. The rationales for these developments were to increase personalisation, reduce the amount of structure in the ePortfolio and increase the opportunity for peer dialogue in the application to help meet the changing expectations of learners who are increasingly familiar with social networking and other Web 2.0 applications. 


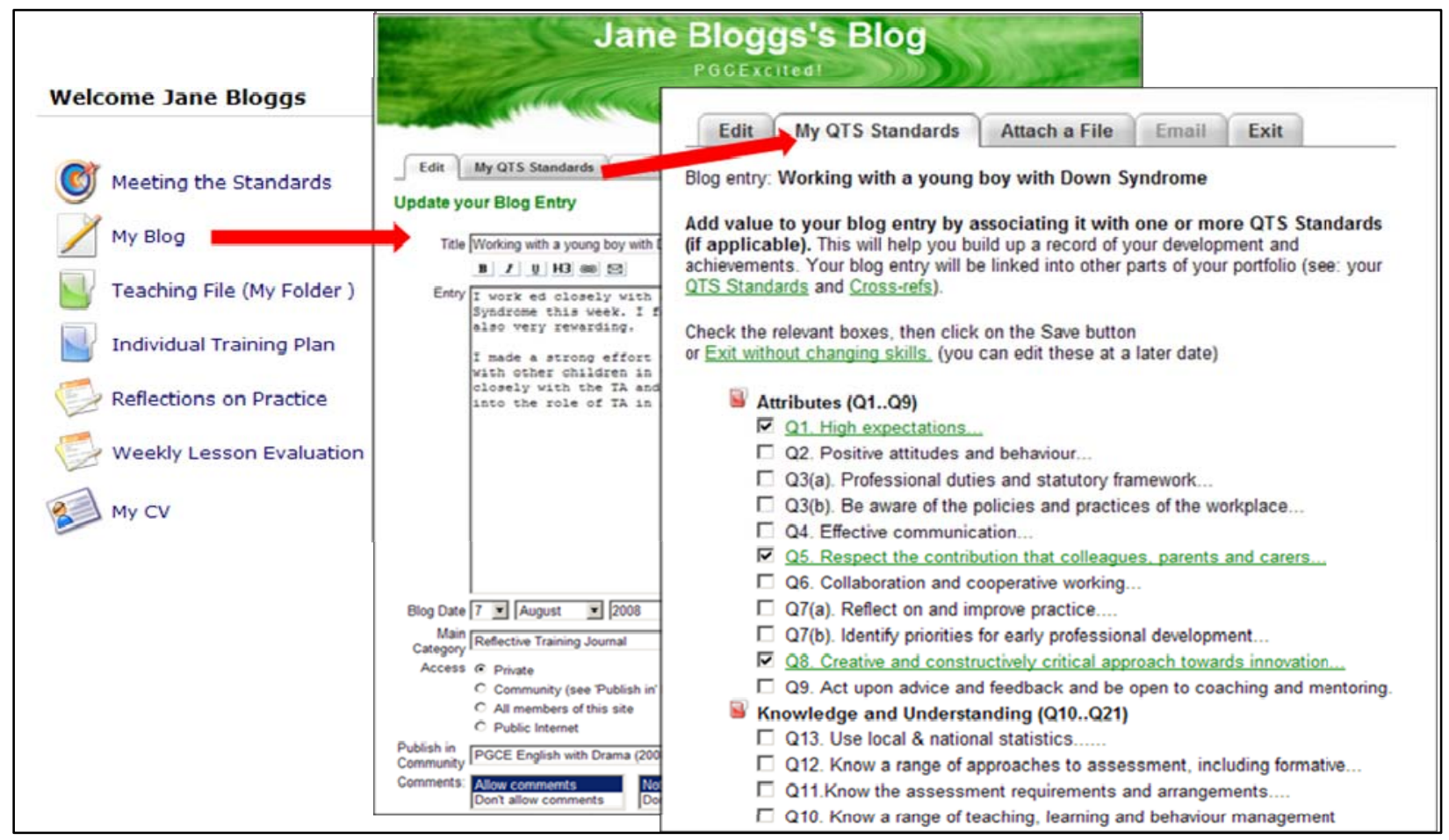

Figure 1. Three partial screen shots: a) initial menu; b) editing a blog entry; c) linking the blog entry to multiple QTS standards.

The programme-level customisation of the e-Portfolio was utilised so that the QTS standards were incorporated, including a description of each standard and a link to the relevant section on the TDA site. These standards and descriptions were available through the structured evidence section of the portfolio and learners could link their blog entries to specific QTS standards (Figure 1). Sections of the portfolio were given labels suited for the context ('My Evidence' changed to 'Meeting the Standards', 'My Folder' changed to 'Teaching File'). In 2008 new sections were created ('Reflections on Practice', 'Weekly Lesson Evaluations' and 'Progress Timeline and action Plan'). These were modelled on an established paper-based portfolio used for ITT at Newcastle. The 'Reflections on Practice' (commonly referred to as 'Reflective Teaching Journal'/RTJ) and 'Weekly Lesson Evaluations' were part of the general blog, but incorporated brief guidance text and preselected the category assigned to each blog entry. As with the general blog, the learner had the option to link each entry with a QTS standard.

\section{Action research approach}

This is a longitudinal study taking an action research approach with adjustments to both technology and pedagogy over a three year period. This included minor adjustments within 
an academic year in response to feedback from both students and staff, and larger design changes between academic years. The main evaluations were based on an electronic questionnaire administered to students in January 2009 which included both fixedresponse and open-ended questions, and analysis of usage statistics. A six point Likert scale was used for non-categorical fixed-response questions, and for summary purposes the proportion agreeing is based on an aggregation of 'weakly agree', 'agree' and 'strongly agree'. In addition, in-course evaluation has also been utilised, and self-selected students discussed issues and provided feedback in two informal focus group drop-in sessions (2008 and 2009). A short questionnaire with open-ended questions was sent to tutors after the $2008 / 9$ year.

\section{Year 1: single subject pilot}

The blog was initially piloted with twenty students and a tutor in a single subject (Secondary English with Drama) in the academic year 2007/8. The blog was introduced to students as part of a hands-on session facilitated by the learning technologist and subject tutor. As part of their use of the blog, the students were asked to discuss key educational articles with the tutor or a student posting a blog entry about the article to the community, and the students were then encouraged to respond with comments about the article or issues raised in other comments. Small adjustments to the software, including 'bug-fixing', were made in response to student feedback during the year. Evaluation of the blog took place as part of an in-course evaluation session; the students were asked to write comments on an anonymised sheet of A4 paper under three headings - plus, minus, and interesting. Text from the evaluation was categorised and results of this qualitative analysis are provided in Table 1.

Table 1. Qualitative analysis of $2007 / 8$ evaluation $(n=20)$.

\section{$\underline{\text { Plus }}$}

Theory/ideas

Social discussion

Reflection

Seeing other perspectives 7

Supporting assessment 4 
Informal 3

$\underline{\text { Minus }}$

Time 16

Technical problems 9

Access to Internet 1

Low engagement by some 1

Topics too guided?

Interesting

Seeing other perspectives 11

Discussion 4

Use blogs in my teaching 4

Others' experiences 2

Reflection 2

Use of theory and Ideas 2

\section{Year 2: roll-out of e-Portfolio}

Based on the evaluation of the single subject pilot, the tutors decided to roll out the ePortfolio to all thirteen Secondary PGCE programmes at Newcastle University. There was a broadening of the scope of the e-Portfolio with increased emphasis on evidencing of the QTS, with trainees requested to provide three items of evidence for each standard (with one item potentially being used to evidence multiple standards). Further sections were added to the e-Portfolio, reflecting a previous paper-based portfolio. In addition to the groups based on the seven disciplinary areas, students were also assigned to crosssubject seminar groups led by a tutor, and to a global 'PGCE community'.

\section{Year 3: further refinements}

The e-Portfolio was largely unchanged from the previous academic year, though better support for sharing blogs with tutors was introduced (part way through the year). The 
cross-subject community groups were dropped. Students were assigned to disciplinebased communities and the overall PGCE community.

\section{Results}

Usage and data statistics for the 2008/9 academic year are shown in Table 2. All students used the e-Portfolio and the mean number of logins was sixty three (the range being from 4 to 253). Of the 4,124 blog entries made, $67 \%$ were linked to one or more QTS standards, and on average each blog entry was linked to five standards. Thirty-six percent of blog entries were posted to a community, mostly the community of all PGCE students or to subject communities, but few to the cross-subject seminar groups. Where comments were made to blog entries, these were mostly within the subject communities, with very few in the community of all PGCE students.

Table 2. Summary student usage and data statistics for the $2008 / 9$ academic year.

\begin{tabular}{|l|l|l|}
\hline Number of students & 154 & \\
\hline $\begin{array}{l}\text { Number of logins: } \\
\text { Total }\end{array}$ & 9,687 & $(4-253)$ \\
\hline $\begin{array}{l}\text { Average (range) } \\
\text { Total }\end{array}$ & 63 & \\
$\begin{array}{l}\text { Average per student } \\
\text { Word count average } \\
\text { (range) }\end{array}$ & $\begin{array}{l}27 \\
\text { Blog categories: }\end{array}$ & $(7-3,420)$ \\
\hline $\begin{array}{l}\text { Reflective Training } \\
\text { Journal } \\
\text { Weekly Lesson } \\
\text { Evaluations } \\
\text { Unclassified } \\
\text { Other }\end{array}$ & 2,450 & $(59 \%)$ \\
\hline $\begin{array}{l}\text { Blog entry postings: } \\
\text { Private }\end{array}$ & 884 & $(21 \%)$ \\
\hline
\end{tabular}




\begin{tabular}{|l|l|l|}
\hline PGCE community & 841 & $(20 \%)$ \\
Subject community & 582 & $(14 \%)$ \\
Seminar group & 67 & $(2 \%)$ \\
\hline $\begin{array}{l}\text { Comments on blog } \\
\text { entries in: }\end{array}$ & \\
$\begin{array}{l}\text { PGCE community } \\
\text { Subject community } \\
\text { Seminar group }\end{array}$ & 411 & $(1 \%)$ \\
\hline $\begin{array}{l}\text { Files uploaded: } \\
\text { Number of files } \\
\text { Individuals who } \\
\text { uploaded }\end{array}$ & 40 & $(90 \%)$ \\
\hline $\begin{array}{l}\text { Evidence linked to QTS } \\
\text { standards: }\end{array}$ & 100 & \\
Blog entries & $13 \% 5$ & \\
Files & 707 & \\
URL links & 13 & \\
\hline
\end{tabular}

Thirty-six percent of students completed the online questionnaire. A summary of responses to key fixed-response questions is provided in Table 3. All respondents personally owned a laptop or desktop PC and all had broadband connections at their place of residence. Of those who responded, $77 \%$ felt that the e-Portfolio had helped them reflect on their learning and development (23\% weakly agreed, 36\% agreed and 18\% strongly agreed).

\section{Table 3. Summary of responses to selected fixed-response questions (2008/9} cohort).

\section{Question}

I have a clear understanding of the purpose of the e-Portfolio $88 \%$

I had a clear understanding of the skills being evidenced in the e-Portfolio $60 \%$

The skills included in the e-Portfolio are important in studying for my degree $68 \%$ The e-Portfolio is important for my programme 
The e-Portfolio is easy to use

It was easy to link blog entries to evidence my skills/competencies $\quad 67 \%$

I have built up a good evidence of my skills using the e-Portfolio $\quad 64 \%$

Using the e-Portfolio helped me reflect on my learning and development $\quad 77 \%$

I would feel comfortable with sharing most of my blog entries with course-mates $29 \%$

I would feel comfortable with sharing most of my blog entries with tutors $\quad 94 \%$

! would feel comfortable posting most of my blog entries on the public internet $\quad 13 \%$

Did you view other people's postings and comments in the community areas? $\quad 97 \%$

Did you contribute postings or comments in the community areas? $66 \%$

It was useful to see other perspectives in the community discussion $\quad 59 \%$

Participating in the community discussions helped my learning $\quad 52 \%$

Emerging themes and illustrative answers to open-ended questions are provided in Table 4 (What did you most like about the e-Portfolio? What did you least like about the ePortfolio? Do you have any other comments about the e-Portfolio/blog/community areas?).

Table 4. Sample of responses to open-ended questions by theme.

\section{$\underline{\text { Reflection }}$}

The portfolio made me find the time to think more about my teaching. The RTJ helped me get into the habit of reflection.

[It was] good to read about each other's experiences, and use it to creatively reflect on what we have done/read.

I like the reflection side, I also think it is useful to look back on early weeks and refresh your memory. I like that the QTS standards are attached to the e-Portfolio as this helps me keep track.

It's nice to have...a hard copy of the developments you have gone through during your teaching experience, however, in many ways it just regurgitates thought processes you are going through. With teaching preparation, 9-5 lectures (not 
getting home till well after $6 \mathrm{pm}$ ) and also TDA key skills tests it sometimes feels superfluous.

It is tedious having to fill in a weekly blog especially when I have many other things to do.

\section{$\underline{\text { Time constraints }}$}

It was quite difficult to blog and prepare for teaching at times, though I did manage.

Too time consuming while actually on placement.

There are too many sections and bits to fill in a busy work schedule.

\section{Evidencing}

What I do like about the e-Portfolio is that it is designed for the purpose of building a skills repertoire, and allows you to connect thoughts and experiences to the Key Skills.

Being able to click on standards at the end of the RTJ to link through, helps keep a record as you go along. Having most of the evidence in one place.

\section{Community/discussion}

Other people's school experiences were written about which helped us make sense of our own lessons.

Being able to discuss issues with other peers was really useful.

Good way to stay in touch with peers during placements and feel you are not alone!

Provides us with a forum for sharing files and resources if we wish. 
The private blog is quite useful to keep yourself on track but I do not feel happy using a public blog at present.

I have only used the community blogging when asked to participate in a task. I did not find this useful.

It's a bit boring to post, as not many people comment. And I find the common area all subjects - not interesting, as the other subjects are having a complete different experience.

[There was a] lack of interest and engagement from some ITT students.

\section{Tutor / pedagogy}

RTJ blogs were useful to me, as I was reflecting on my own practice. I keep these private, but have given access to my tutor, which I think is a good idea.

It may be interesting to focus and emphasise the blog/e-Portfolio as more public and communicative tool. If tutors were for example to highlight a theme/issue for the week, i.e. how can you cater for SEN pupils in your lessons? Or how does Autism effect learning?, to which we post out responses to show that we are engaging with these things and learning from one another, demonstrating collaborative learning.

We could...talk about personal scenarios and experiences we've had. Tutors could then highlight what theory says and comment on these, so that we students are not just left to juggle our ideas without any idea of what academic research says. I'm aware there are not 'answers' as such, but I feel tutors should have more input.

[It was] an interesting way of analysing yourself and your thoughts. It has been a kind of learning journal extension, but with a critical reference to theory.

\section{$\underline{\text { Other }}$}

Makes me think about how I could use something like this with students as a learning tool. 
Thinking about using blogging in my teaching. New thing for me, but it has been helpful.

Being able to access it online easily, it was easy to write whenever I wanted to and come back to it to add bits later.

You could save your blog entries and go back to them later.

Easy to use and I have the option to keep things I type private.

I liked that you could personalise the e-Portfolio.

It's not very clear exactly what parts of it are mandatory and what parts are optional.

Not very clear where and what to write. I found it easier to use paper and pen.

A word count and spell check would be a useful feature.

\section{Social networking}

The vast majority of students responding to the questionnaire (89\%) used external social networking sites; predominantly Facebook. These were used primarily for staying in touch with friends (88\%), sharing photos, music and video (73\%), and finding out more about people (57\%). Fewer (24\%) considered it a forum to express their opinions and views and few $(6 \%)$ as a way of making new friends with people they had never met in person.

Many (47\%) had used social networking to communicate with classmates about courserelated topics, few (12\%) to communicate with teaching staff about course-related topics. However, a frequent theme in the open-ended question about social networking in education was that social and work lives should be separate. Some students made a distinction between formal learning/reflection on the institutional site and informal discussion on external social sites (see illustrative comments in Table 5). 
Table 5. Selected responses to the question 'Any thoughts or comments on the use of social networking sites in education?'.

I prefer to keep social networking sites for personal use and for engaging in general conversation about essays etc. in a non-official/non-university domain where it's friends discussing a course. Professional dialogue, opinions on educational matters, lesson plans, theory discussions I prefer to engage in face-to-face or via the official, nominated online spaces. Social networking sites are for personal use and should not be confused with professional use.

To be honest I think academic life and social life should be divided where possible. Course-mates will naturally join together on sites such as Facebook, and may discuss ITT issues using Facebook, but universities shouldn't expect to start up their blog forums on such sites.

It could have a place. We were encouraged to discuss work in the e-Portfolio and this was completed (if a little clinically). However, there were a few informal discussions about school and university work taking place on Facebook, which more people were contributing to. These involved discussing work to be done, shared experiences in school placements etc. And I feel that these were just as important to our developing practice.

\section{Staff perceptions}

Issues raised by teaching staff in meetings with tutors and the learning technologist, and from staff responses to a short questionnaire, are shown in Table 6. There were some differences in emphasis between individual staff (some more focussed on community/support and others on evidencing/monitoring) and issues changed over time. A key problem for tutors related to access to students' portfolios. Unlike the rest of the sections of the e-Portfolio which can be shared on an individual basis, e.g. between a student and their tutor, the blog had been modelled on sharing with groups/communities. Therefore, additional work was needed to enhance sharing of blogs with tutors. This was not ready until part way through 2009. 


\section{Table 6. Sample of staff responses (2009).}

\section{$\underline{\text { Potential Benefits }}$}

Setting online seminars to discuss set articles when group on placement. Providing support network run by and for students.

Communication with students, peer support and tracking of progress by both tutor and student.

Links that can be generated between different aspects of students' experience; ultimately should save time; and there are benefits in having so much in one place.

\section{Motivation/benefits for students}

Hopefully that [the blog] format would seem familiar to them and that they would see it as a means of accomplishing something complex in a more straight forward fashion.

Many of them prefer to save and share work in this way - e.g. their teaching resources tend to be largely electronic.

I think [blogging to the community] is very worthwhile, especially with regards to the nature of Secondary PGCE, where subjects groups can be become isolated from each other; it encourages the wider sharing of good practice and professional development and, again, provides a wider support network for students.

\section{$\underline{\text { Main motivation for tutors }}$}

Enables us to see links that were not previously evident...Sitting together with the student and viewing their e-Portfolio on the computer screen provided a helpful focus for end of phase one tutorials - and talking us through their e-Portfolio gave students something concrete to do! 
That for the Secondary PGCE it would allow us to have shared discussions with our students regarding their progress towards 'Meeting the Standards' or going beyond them rather than the process being one of checking that there were 'sufficient' pieces of paper in files.

\section{Concerns}

Technical problems.

Concerns about whether the substance could be shared with school colleagues and danger of ending up with two systems - paper and electronic.

I do not think at present we can carry out our monitoring role effectively using the system as although we can see [blog entries have] been indicated as being evidence for the standards we cannot open [them all] (2008/9).

We did not explain its operation clearly enough to the students - some of whom are still in a state of confusion...An electronic guide has been suggested for next year.

\section{Discussion}

Though the nature of reflection and critical reflection is often ill-defined (Hatton and Smith, 1995), there is a general acceptance in education that reflection is a 'good thing', with potential to aid the transition from surface to deep learning, and being a an important component of experiential learning (Kolb, 1984) and of independent continuing development. The emergence of e-Portfolio, blogging and social network technologies have applicability for supporting reflection and also assessment, and for enhancing communications. The technologies and changing experiences and expectations of technology bring to the forefront questions relating to tensions between reflection and assessment, and also issues around the context of developing reflection as either an isolated private activity, something shared with a tutor/coach, or as an open activity within a 'learning community'. 
Use of e-Portfolios is becoming more widespread in education but it is important to recognise that the term represents a broad spectrum of technologies, with differing levels of structure designed to support different pedagogies and different purposes (such as reflection, assessment, personal publishing, and forward planning). Likewise, there is variation in blogging and social networking, though these tend to be less structured and more public facing than e-Portfolios. The blog within the e-Portfolio developed at Newcastle University provides a novel way of linking reflection and evidencing skills/standards, possibly reducing the tension between these. Whilst there is good practice in the use of blogs in education, a common shortfall is that learners often don't use free-text tagging (categorisation) or use it inconsistently. This can be problematic if a sub-set of blog entries needs to be used for a specific purpose, such as assessment (Mason, 2007). The problem is especially acute with standards such as TQS, which tend to have lengthy titles for each standard, which would be difficult to record consistently with free text tagging. It was our aim to link unstructured blog entries with structured outcome/skill sets, with blog entries linked with standards being automatically crossreferenced in the evidence ('Meeting the Standards') area of the portfolio.

There can sometimes be a tension between reflection and assessment (Hilsdon, 2006). For example, reflective portfolios are often considered private, in which mistakes and weaknesses may be openly acknowledged, whilst portfolios for assessment have more emphasis on positive evidence for achievement of competencies, written for an assessor and structured around predefined criteria. Recent advances in e-Portfolio technologies may potentially lessen the tensions between reflection and assessment, by providing greater control to the learner over which of their entries are public, compared to a paper journal. In addition, technologies may provide opportunities for reducing duplication of documentation, for example, an entry in the 'Weekly Lesson Evaluations' may also be cross-referenced with multiple standards as evidence in the 'Meeting the Standards'.

The use of technology to support reflection brings the option to open up reflections to a wider audience, with the potential for new opportunities for interaction and conversation. This may be in addition to, or complementary to, coaching and feedback from tutors aimed to develop learners' skills in reflection and critical reflection. At Newcastle the PGCE students have engaged with blogging community areas and shared blog entries considerably more than students on other programmes (Cotterill et al., 2009). However, many PGCE students were uncomfortable with sharing their blog entries with their peers. 
On the other hand nearly all students did read the blog entries of their peers posted in the community areas and many found it useful to see the perspectives of others (see Tables 3 and 4). In particular, the qualitative data suggests that students strongly valued seeing the reflections and thoughts of their peers in the context of discussions around educational theory and relating theory to experiences in teaching practice - although less so with 'ad hoc' postings from students in other teaching subject areas. A recent study of teacher education in Queensland found that making reflection public had a positive impact on the quality and style of reflection (Rocco, 2010); trainees valued seeing multiple perspectives, which built up confidence and competence for engaging in reflection and professional dialogue.

Blogging is usually a form of public publishing, however, private blogging (for example within a VLE or other password protected environment) can be argued to give trainees the confidence to post entries without the fear of them being read by anyone else other than their tutor (Hramiak et al., 2009). Others have taken the opposite approach, using blogging environments where all posts are visible to all members to encourage trainees to 'go out there and express an opinion' helping to develop both individuals and the 'collective learning network' (Bartlet-Bragg, 2006). With this approach some individuals take to it straight away but many initially find it intimidating and lack confidence in publishing to the group. In this study the individual has control over which of their blog entries remain private, with the opportunity and expectation that they will contribute to the wider group.

This paper documents the growing maturity in both pedagogy and technology in the use of e-Portfolios/blogs and changes over a three year period in an ITT context. Implementing ePortfolios can take time, usage, and numerous adjustments in response to feedback in order to achieve a 'good fit' to the curriculum (Arter and Spandel, 1992). Engagement with the e-Portfolio has been good in relation to many other subjects (Cotterill et al., 2009). Most students understood the purpose and rationale of the e-Portfolio in relation to the skills/standards being evidenced, recognised that it was valued by their programme and promoted by staff (Table 2), and that the portfolio was embedded in the curriculum and activities - all favourable factors for engagement. The study indicates the approach was successful in supporting reflection and evidencing, but the discussion/dialogue element was mixed and mostly confined within subject groups. Some subject groups had more conversation than others, indicating the role of tutors and/or individual learners in initiating and engaging in discussion. A sub-set of students did actively engage in informal 
discussion on external social networking sites. Elsewhere, engagement and effective learning from discussion has been shown to depend on clarity of purpose: 'students who do not understand how discussions can help them to interrogate, reflect on and revise their ideas tended not to approach either face-to-face or online discussions in ways likely to improve their understanding or their levels of achievement' (Ellis et al., 2007, p.83).

Limitations to this study include a modest response rate by the students (37\%). It is also acknowledged that the practitioners are involved in both design/development and evaluation, as is the nature of an action research approach. The study indicates that the ePortfolio/blog supports reflection, but it is not in the scope of this paper to address the depth and quality of the reflection. As reported elsewhere, considerable variability in quantity and quality of student reflection is not unusual (Hramiak et al., 2009).

\section{Conclusions}

The e-Portfolio described here provides a novel approach of linking an unstructured blog to a structured set of skills/standards which has been used extensively by participants in this study. A large proportion (77\%) of the students perceived that the e-Portfolio helped them to reflect on their learning and development. Encouraging dialogue by giving students the option to publish blog entries to communities has had mixed success, with most conversation restricted within subject groups. Overall engagement with the ePortfolio has been reasonably high, compared with many other subjects. Factors thought to promote engagement in this context include a reasonably good clarity of purpose, active promotion and buy-in from tutors, and the fact that students understood and related to the standards being evidenced. A significant sub-set of students (47\%) concurrently engaged with peers in an external social networking site, some making the distinction between informal discussion on Facebook and formal learning and reflection in the e-Portfolio, whilst others wanted to keep work and social lives separate.

\section{Acknowledgement}

This paper is an outcome of the National Action Research Network on researching and evaluating Personal Development Planning and e-Portfolio practice project (2007-2010). 
The project was led by the University of Bolton in association with the University of Worcester and Centre for Recording Achievement, and in national collaboration with the University of Bedfordshire, Bournemouth University and University of Bradford. The project was funded by the Higher Education Academy, National Teaching Fellowship Project strand. More details about the project can be found at: http://www.recordingachievement.org/research/narn-tree.html.

The study also built on software developed as part of JISC funded 'EPICS-2' regional ePortfolios project.

\section{References}

Arter, J. and Spandel, V. (1992) 'Using portfolios of student work in instruction and assessment', Educational Measurement: Issues and Practice, 11(1), pp. 36-44.

Bartlet-Bragg, A. (2006) 'Reflections on pedagogy: Understanding adult learners' experiences of weblogs', BlogTalk Reloaded. Vienna, Austria 2-3 October [Online]. Available at: http://2006. blogtalk.net/ (Accessed: 12 June 2010).

Cotterill, S.J., Horner, P., Hammond, G.R., McDonald, A.M., Drummond, P., Teasdale, D., Aiton, J., Orr, G., Bradley, P.M., Jowett, T., Heseltine, L., Ingraham, B. and Scougall, K. (2005) 'Implementing e-Portfolios: adapting technology to suit pedagogy and not vice versa!', Conference Proceedings: ePortfolio 2005. Cambridge 26-28 October.

Cotterill, S.J., Aiton, J., Bradley, P.M., Hammond, G., McDonald, A., Struthers, J. and Whiten S. (2006) 'A flexible component-based ePortfolio: adapting and embedding in the curriculum', in Jafari, A. and Kaufman, C. (eds.) Handbook of research on ePortfolios. Pennsylvania: Idea Group Inc, pp. 292-304.

Cotterill, S.J., Horner, P., Gill, S., McDonald, A.M., Drummond, P., Teasdale, D., Whitworth, A. and Hammond, G.R. (2007) 'Beyond the Blog: getting the right level of structure in an ePortfolio to support learning', Conference Proceedings: ePortfolios 2007. Maastricht 18-19 October. 
Cotterill, S.J., Horner, P., McDonald, A.M., Drummond, P., Teasdale, D., Moss, J. and Hammond, G. (2008) 'A blog for learning: blogs and social networking with explicit support for skills and learning outcomes, within an integrated ePortfolio', in Conference Proceedings: ePortfolios, identity and personalised learning in healthcare education. Newcastle upon Tyne 28 February. Newcastle upon Tyne: HEA Subject Centre for Medicine, Dentistry and Veterinary Medicine, pp. 91-96. ISBN 978-1-905788-66-2.

Cotterill, S.J., Horner, P. and Edney, M. (2009) EPICS-2: North East regional collaboration for personalised, work-based, and life-long learning. Final project report. Available at: http://www.epics.ac.uk/report (Accessed: 15 June 2010).

Ellis, R., Goodyear, P., O'Hara, A. and Prosser, M. (2007) 'The university student experience of face-to-face and online discussions: coherence, reflection and meaning', ALT-J, 15(1), pp. 83-97.

Hatton, N. and Smith, D. (1995) 'Reflection in teacher education: towards definition and implementation', Teaching and Teacher Education, 11(17), pp. 33-49.

Hilsdon, J. (2006) 'Re-thinking reflection', Journal of Practice Teaching in Health and Social Work, 6(1), pp 57-70.

Hramiak, A., Boulton, H. and Irwin, B. (2009) 'Trainee teachers' use of blogs as private reflections for professional development', Learning, Media and Technology, 34(3), pp. 259-269.

Kolb, D.A. (1984) Experiential learning: experience as the source of learning and development. Englewood Cliffs, N.J: Prentice-Hall, Inc.

Mason, R. (2007) 'ePortfolio for professional development', Conference Proceedings: ePortfolios 2007. Maastricht 18-19 October.

Rocco, S. (2010) 'Making reflection public: using interactive online discussion board to enhance student learning', Reflective Practice, 11(3), pp. 307-317. 
Training and Development Agency for Schools (TDA) (2007) QTS standards and ITT requirements. Available at: http://www.tda.gov.uk/partners/ittstandards.aspx (Accessed: 15 June 2010).

\section{Author details}

Simon Cotterill is a Senior Research Associate and Learning Technologist in the School of Medical Sciences Education Development at Newcastle University.

Karen Lowing is a Teaching Fellow and PGCE Tutor for English and Drama in the School of Education, Communication and Language Sciences at Newcastle University.

Karl Cain is Programme Leader and PGCE Tutor for History in the School of Education, Communication and Language Sciences at Newcastle University.

Rachel Lofthouse is Head of Teacher Learning and Development and PGCE Tutor for Geography in the School of Education, Communication and Language Sciences at Newcastle University.

Cheryl Mackay is a Lecturer and PGCE Tutor for Modern Languages in the School of Education, Communication and Language Sciences at Newcastle University.

Joanne McShane is a Teaching Fellow in Education and PGCE Tutor for R.E. in the School of Education, Communication and Language Sciences at Newcastle University.

David Stancliffe is a Teaching Fellow and PGCE Tutor for Sciences in the School of Education, Communication and Language Sciences at Newcastle University.

David Wright is a Teaching Fellow and PGCE Tutor for Maths in the School of Education, Communication and Language Sciences at Newcastle University. 